\title{
The Origin of the Complex Spike in Cerebellar Purkinje Cells
}

\author{
Jenny T. Davie, Beverley A. Clark, and Michael Häusser \\ Wolfson Institute for Biomedical Research and Department of Neuroscience, Physiology, and Pharmacology, University College London, London \\ WC1E 6BT, United Kingdom
}

\begin{abstract}
Activation of the climbing fiber input powerfully excites cerebellar Purkinje cells via hundreds of widespread dendritic synapses, triggering dendritic spikes as well as a characteristic high-frequency burst of somatic spikes known as the complex spike. To investigate the relationship between dendritic spikes and the spikelets within the somatic complex spike, and to evaluate the importance of the dendritic distribution of climbing fiber synapses, we made simultaneous somatic and dendritic patch-clamp recordings from Purkinje cells in cerebellar slices. Injection of large climbing fiber-like synaptic conductances at the soma using dynamic clamp was sufficient to reproduce the complex spike, independently of dendritic spikes, indicating that neither a dendritic synaptic distribution nor dendritic spikes are required. Furthermore, we found that dendritic spikes are not directly linked to spikelets in the complex spike, and that each dendritic spike is associated with only $0.24 \pm 0.09$ extra somatic spikelets. Rather, we demonstrate that dendritic spikes regulate the pause in firing that follows the complex spike. Finally, using dual somatic and axonal recording, we show that all spikelets in the complex spike are axonally generated. Thus, complex spike generation proceeds relatively independently of dendritic spikes, reflecting the dual functional role of climbing fiber input: triggering plasticity at dendritic synapses and generating a distinct output signal in the axon. The encoding of dendritic spiking by the post-complex spike pause provides a novel computational function for dendritic spikes, which could serve to link these two roles at the level of the target neurons in the deep cerebellar nuclei.
\end{abstract}

Key words: climbing fiber; Purkinje cell; cerebellum; dendritic spike; burst; axon

\section{Introduction}

Adult Purkinje cells each receive input from a single climbing fiber (CF), which makes hundreds of synapses across its highly branched main dendrites (Palay and Chan-Palay, 1974). CF activation produces a distinctive high-frequency burst of spikes: the complex spike (Eccles et al., 1966; Fujita, 1968; Llinás and Sugimori, 1980b), which is thought to represent a critical signal for the operation of the cerebellar cortex, conveying both timing information (Welsh and Llinás, 1997) and triggering synaptic plasticity (Gilbert and Thach, 1977; Hansel et al., 2001; Ito, 2001). Understanding complex spike generation is therefore essential for understanding information processing and plasticity in Purkinje cells.

The mechanism of complex spike generation has been debated for decades (Schmolesky et al., 2002). It is known that, similarly to simple spikes (Stuart and Häusser, 1994; Clark et al., 2005; Khaliq and Raman, 2006), the first spike of the complex spike is generated in the axon (Stuart and Häusser, 1994); both backpropagate only weakly into the dendrites (Llinás and Sugimori, 1980b; Stuart and Häusser, 1994). Purkinje cell dendrites can, however, generate prominent dendritic calcium spikes,

Received Feb. 7, 2008; revised June 1, 2008; accepted June 2, 2008.

This work was supported by grants from the Wellcome Trust, European Commission, and the Gatsby Foundation. J.D. was supported by the Wellcome Trust 4-year PhD Programme in Neuroscience at University College London. We are grateful to Mickey London, Ede Rancz, Arnd Roth, Spencer Smith, and Ikuko Smith for helpful discussions and for their comments on this manuscript.

Correspondence should be addressed to Michael Häusser, Wolfson Institute for Biomedical Research, University College London, Gower Street, London WC1E 6BT, UK. E-mail: m.hausser@ucl.ac.uk. DOI:10.1523/JNEUROSCI.0559-08.2008

Copyright $\odot 2008$ Society for Neuroscience $\quad$ 0270-6474/08/287599-11\$15.00/0 which can propagate toward the soma (Eccles et al., 1966; Llinás et al., 1968; Llinas and Nicholson, 1971). CF input activates dendritic spikes, often in a burst-like pattern (Fujita, 1968; Llinás and Sugimori, 1980b), suggesting an alternative view to the classical hypothesis that the somatic spikelets in the complex spike are generated in the axon (Granit and Phillips, 1956; Eccles et al., 1966). The difficulty in suppressing spikelets in the complex spike by antidromic spike activation (Martinez et al., 1971), together with the finding that secondary spikelets can be modulated independently of the first spike of the complex spike (Campbell et al., 1983), suggested that spikelets in the complex spike could reflect dendritic spikes. However, the fact that somatic bursts of spikes can be triggered without significant dendritic calcium entry, and that inhibition of dendritic spikes only has a weak effect on the somatic complex spike waveform (Callaway et al., 1995; Callaway and Ross, 1997), strongly argues against this interpretation. Nevertheless, the contribution of individual dendritic spikes to the complex spike and the origin of the spikelets within the complex spike remain unresolved. This is important because in other neuronal types, strong links can exist between dendritic spikes and axonal action potentials. In mitral cells and in hippocampal and cortical pyramidal cells, dendritic spikes can trigger one or more axonal action potentials (Chen et al., 1997; Stuart et al., 1997; Golding and Spruston, 1998; Larkum et al., 1999, 2001; Ariav et al., 2003). Moreover, backpropagating axonal action potentials can themselves promote dendritic spikes, a reciprocal interaction that can lead to a burst of axonal action potentials (Pinsky and Rinzel, 1994; Mainen and Sejnowski, 1996; Larkum et al., 1999, 2001; Doiron et al., 2002; Turner et al., 2002; Williams and Stuart, 2002). We have therefore used simultaneous somatic and den- 
A

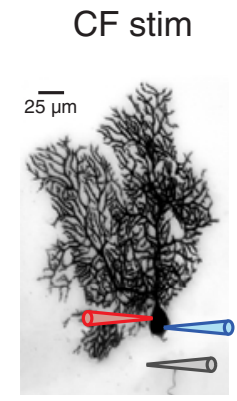

B
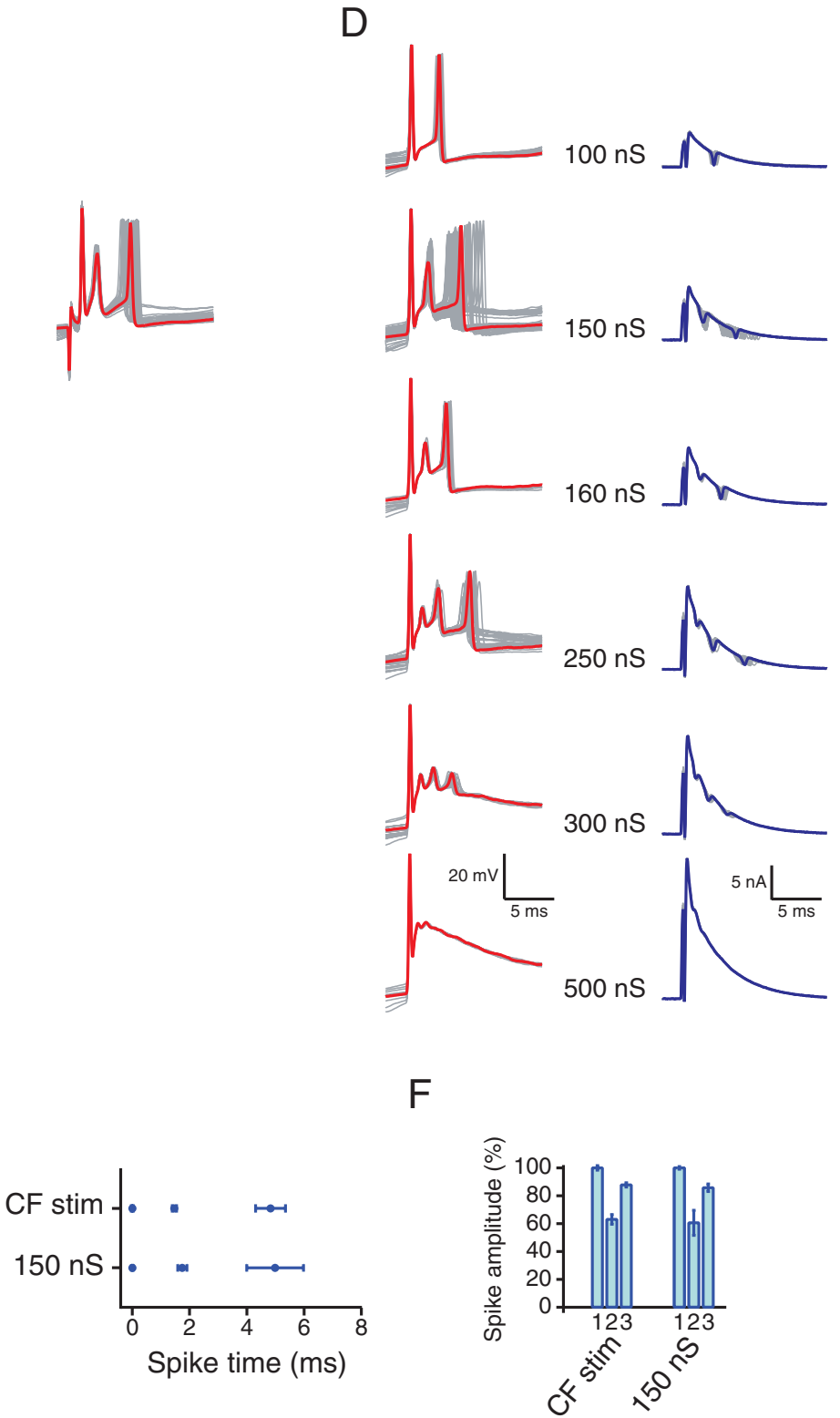

Figure 1. Complex spikes triggered by CF stimulation can be reproduced by somatic dynamic clamp. $\boldsymbol{A}$, Recording configuration illustrated using an image of a biocytin-filled Purkinje cell. Somatic electrodes (blue and red) and a (F-stimulating electrode in the granule cell layer (gray) are shown. $\boldsymbol{B}$, Complex spike responses of Purkinje cell shown in $\boldsymbol{A}$, evoked by $1 \mathrm{~Hz}$ stimulation of its CF. Overlay of multiple sweeps (gray) and a single representative example (red). C, Simultaneous dual somatic dynamic-clamp configuration, with one electrode used to record voltage (red) and the other to inject current (blue). $\boldsymbol{D}$, Responses (left) of the same cell as in $\boldsymbol{A}$ to injection of synaptic-like conductances of increasing amplitude (right, biexponential waveform, $\tau_{\text {rise }}=0.3 \mathrm{~ms}$, dritic or somatic and axonal recording to directly investigate the link between dendritic, somatic, and axonal events during complex spike generation in Purkinje cells.

\section{Materials and Methods}

Slice preparation. Parasagittal slices (200-300 $\mu \mathrm{m})$ of postnatal day 18 (P18)-P24 rat cerebellum were made according to standard techniques (Geiger et al., 2002; Davie et al., 2006). All procedures were approved by the United Kingdom Home Office. Artificial CSF (ACSF) for both slicing and recording contained the following (in $\mathrm{mm}$ ): $125 \mathrm{NaCl}, 2.5 \mathrm{KCl}, 26$ $\mathrm{NaHCO}_{3}, 1.25 \mathrm{NaH}_{2} \mathrm{PO}_{4}, 25$ glucose, $1 \mathrm{MgCl}_{2}$, and $2 \mathrm{CaCl}_{2}$, and was bubbled with $5 \%$ carbon dioxide, $95 \%$ oxygen. Slices were continuously superfused with ACSF during the experiment, and all experiments were performed at $34-35^{\circ} \mathrm{C}$

Electrophysiology. Simultaneous whole-cell patch-clamp recordings from both soma and dendrites were made under direct visual control (Davie et al., 2006) using differential interference contrast optics (Zeiss Axioskop). Patch electrodes were pulled to resistances of $4-5 \mathrm{M} \Omega$ (for the soma) or 7-10 $\mathrm{M} \Omega$ (for the dendrites) from thick-walled, filamented borosilicate glass. Internal solution (280-285 mOsm) contained the following (in mM): $133 \mathrm{KMeSO}_{4}, 7.4$ $\mathrm{KCl}, 0.3 \mathrm{MgCl}_{2}, 10$ HEPES, 0.1 EGTA, 3 $\mathrm{Na}_{2}$ ATP, and $0.3 \mathrm{Na}_{2} \mathrm{GTP}$, pH adjusted to 7.2 with $\mathrm{KOH}$, to which $0.5 \%$ biocytin was usually added. Current-clamp recordings were made using both AxoClamp 2B and 2A amplifiers (Molecular Devices), and were low-pass filtered at $3 \mathrm{kHz}$ before being sampled at $20-50 \mathrm{kHz}$ using Axograph 4.9 software (Axograph Scientific) and an ITC-18 interface (Instrutech).

CF input was stimulated by placing a patch electrode filled with ACSF in the granule cell layer $(0.2 \mathrm{~ms}, 20-80 \mathrm{~V}$ square pulses; $1 \mathrm{~Hz}$ stimulation frequency). The location of the stimulation electrode and the stimulation intensity were adjusted until an isolated CF input was excited without evoking an antidromic action potential in the Purkinje cell axon. Complex spikes preceded by a simple spike within $\sim 1.5$ ms were excluded from analysis because these were found to have a disrupted complex spike pattern. In some experiments, the cell was taken to threshold for generating multiple dendritic spikes in response to CF stimulation by varying the tonic current injection at the soma ( -600 to $900 \mathrm{pA})$.

For simultaneous somatic and axonal recordings, whole-cell recordings were first made

$\leftarrow$

$\tau_{\text {decay }}=3 \mathrm{~ms}$, peak amplitudes as indicated beside traces). Note that by choosing the appropriate conductance amplitude ( $150 \mathrm{nS})$, the complex spike evoked by (F stimulation could be mimicked. $\boldsymbol{E}, \boldsymbol{F}$, Timing $(\boldsymbol{E})$ and amplitude $(\boldsymbol{F})$ of spikes (measured with respect to the first spike, for the first, second, and third spikes) within the complex spikes evoked by (F stimulation and by the $150 \mathrm{nS}$ synaptic-like conductance. Spike times differed by $<17 \%$; amplitudes differed by $<4 \%$. stim, Stimulation. 
A

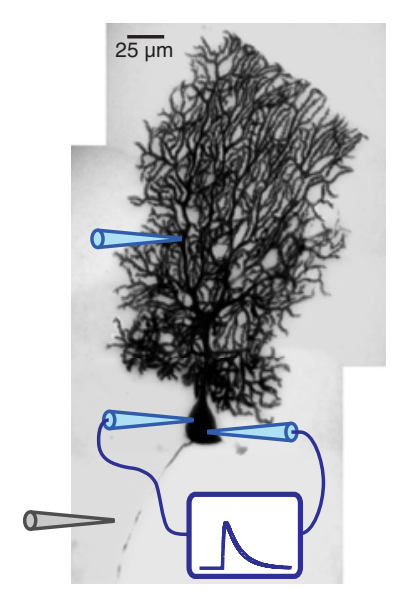

B
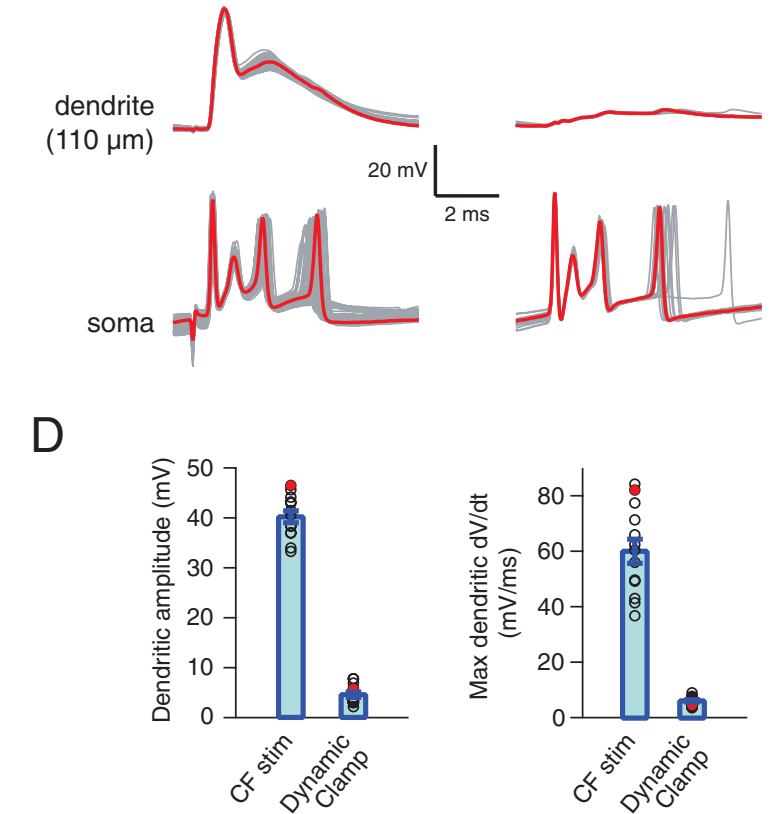

C CF stim Dynamic Clamp

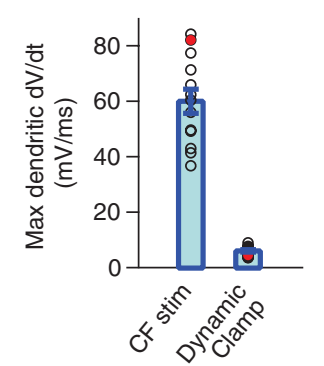

Figure 2. Dendritic spikes are not necessary for the generation of the complex spike. $\boldsymbol{A}$, Simultaneous dendritic and somatic patch-clamp recording (blue electrodes) during both climbing fiber stimulation (gray electrode) and two-electrode somatic dynamic clamp. $\boldsymbol{B}$, CF response of cell shown in $\boldsymbol{A}$ recorded simultaneously at the soma (bottom traces) and $110 \mu \mathrm{m}$ away in the dendrites (top traces). Complex spikes at the soma are accompanied by characteristic dendritic calcium spikes. $C$, Response of same cell to $150 \mathrm{nS}$ somatic dynamic clamp. Somatic complex spikes generated by dynamic clamp are well matched to CF-evoked responses (spike times differed by $<18 \%$, amplitudes by $<10 \%$ ), but no dendritic spikes are observed. $\boldsymbol{D}$, Average amplitude and $d V / d t$ of dendritic events triggered in response to CF stimulation or equivalent somatic dynamic clamp $(n=13$ cells; significantly different, $p<10^{-7}$ ). Open circles show single-cell averages (data shown in $\boldsymbol{B}$ and $\boldsymbol{C}$ are highlighted in red); bars show the mean \pm SEM of the total data. stim, Stimulation.

from Purkinje cells using the above internal solution containing 45-80 $\mu \mathrm{M}$ AlexaFluor 488, and the CF input was located using an extracellular stimulating electrode as above. The somatic pipette was then retracted carefully to form an outside-out patch, thereby resealing the cell membrane. Two patch electrodes containing $150 \mathrm{~mm} \mathrm{NaCl}$ were then used to make simultaneous loose cell-attached recordings in voltage-clamp mode from the soma and the proximal axon and to record the capacitive currents generated by action potentials (sampling rate, $100 \mathrm{kHz}$ ). The peak of the capacitive current corresponds to the time of the fastest rise of the local action potential and therefore can be used to indicate the relative timing of spikes in the soma and the axon (Clark et al., 2005). Biocytin staining was used for post hoc recovery of cell morphologies.

Dynamic clamp. This method (Robinson and Kawai, 1993; Sharp et al., 1993) was implemented using custom analog hardware (SM-1; Cambridge Conductance). Synaptic-like conductances were applied to the soma using two patch-clamp electrodes (one recording membrane potential, the other injecting current) to avoid bridge balance errors (Williams, 2004). Waveforms were biexponential, with $\tau_{\text {rise }}=0.3 \mathrm{~ms}, \tau_{\text {decay }}=$ $3 \mathrm{~ms}$, peak amplitude of $100-500 \mathrm{nS}$, and a reversal potential of $0 \mathrm{mV}$. In some exploratory experiments, the effect of conductance time course was investigated, varying $\tau_{\text {rise }}$ from 0.2 to $0.5 \mathrm{~ms}$ and $\tau_{\text {decay }}$ from 2 to $5 \mathrm{~ms}$. Complex spike-like events were produced over this entire 2.5 -fold range of kinetics, and changing kinetics did not produce substantial improvements in the match to the physiological complex spike. In some experiments, dendritic spikes were evoked during somatic dynamic clamp; these spikes were triggered by dendritic current injection (biexponential current waveform, $\tau_{\text {rise }}=0.5 \mathrm{~ms}$ and $\tau_{\text {decay }}=5 \mathrm{~ms}$, peak amplitude of 2-5 nA together with tonic current of $0-330 \mathrm{pA}$ ).

Analysis. Data were analyzed using custom programs, together with NeuroMatic data analysis software (http://www.neuromatic. thinkrandom.com/), in Igor Pro (Wavemetrics). The amplitudes of spikelets in the complex spike were measured with respect to baseline membrane potential (averaged over $50 \mathrm{~ms}$ before the complex spike), and the resulting amplitudes were sometimes normalized to the amplitude of the first spike in the complex spike. Somatic spike threshold was taken as the point at which the second derivative of the spike reached $10 \%$ of its peak value during the rising phase of the spike; threshold amplitude was measured as the voltage at this point minus the minimum voltage reached in the preceding trough. Dendritic spike width was measured at half the height of the spike peak above the preceding trough in membrane potential. Attenuation was measured in records in which extra dendritic spikes did not trigger extra somatic spikelets, allowing the depolarization caused by the propagated dendritic spike to be seen in isolation. The amplitude of the propagated event was found by subtracting from these records the average somatic waveform of corresponding responses of a similar somatic spiking pattern but without the extra dendritic spike (see Fig. 5A). Analogously, the amplitude of the dendritic spike was found by subtracting the average dendritic waveform of the same dataset from the individual records with extra dendritic spikes. Attenuation was calculated as the somatic event amplitude as a percentage of the dendritic event amplitude. Spontaneous interspike intervals (ISIs) were calculated as the average of three consecutive intervals between simple spikes occurring in the same trace as the post-complex spike pause. Post-complex spike afterhyperpolarizations (AHPs) were quantified by finding the minimum voltage during the post-complex spike pause in spontaneous firing and subtracting mean baseline membrane potential (as measured above). Differences between groups were tested for statistical significance using Student's $t$ test (paired or unpaired as appropriate). Data were reported as the mean [in some cases weighted by the number of observations in each dataset (Bland and Kerry, 1998)] \pm SEM unless otherwise indicated.

\section{Results}

Somatic dynamic clamp can reproduce the complex spike

Activation of CF input to cerebellar Purkinje cells triggers the highly reproducible pattern of somatic spikes known as the complex spike (Fig. 1A,B) (Eccles et al., 1966; Llinás and Sugimori, 1980a). To determine whether the dendritic distribution of $\mathrm{CF}$ synaptic contacts is necessary to generate the distinctive spiking pattern of the complex spike, we examined whether concentrating the synaptic conductance at the soma is sufficient to mimic the complex spike waveform. Dynamic clamp was used to inject a biexponential conductance, based on the physiological CF synaptic conductance (Perkel et al., 1990; Llano et al., 1991; Silver et al., 1998; Wadiche and Jahr, 2001), via simultaneous dual somatic patch-clamp recordings (Fig. $1 C$ ). By adjusting the amplitude of the somatic dynamic-clamp conductance (Fig. $1 D$ ), a remarkably good match could be achieved with the CF-evoked complex spike (Fig. $1 B$ ). This matching was achievable in most cells, not only in neurons exhibiting complex spikes consisting of relatively few spikes (Fig. 1A), but also for neurons with elaborate complex spikes consisting of $\geq 5$ spikes (see supplemental Fig. 1, available at www.jneurosci.org as supplemental material). The mean value of the "optimal" synaptic conductance was $170 \pm 58 \mathrm{nS}$ (range, 
A

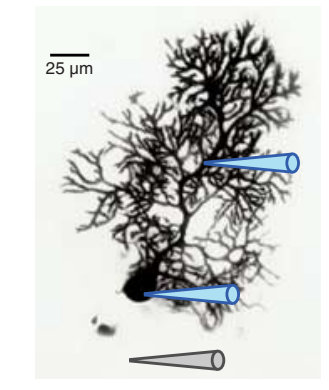

C

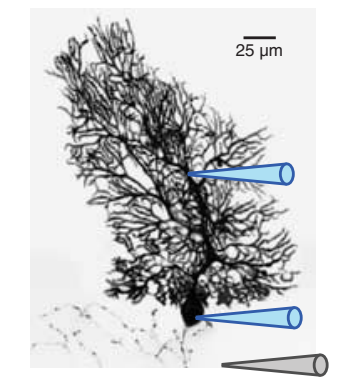

B

\section{1 dendritic spike 2 dendritic spikes}

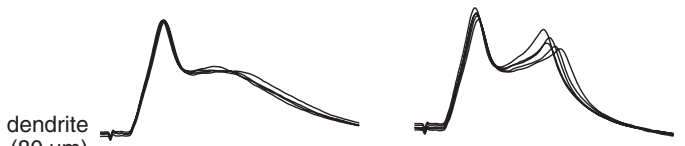

$(80 \mu \mathrm{m})$
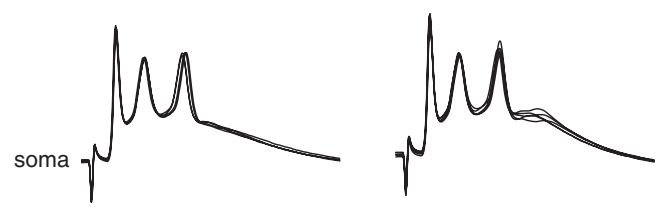

$E$

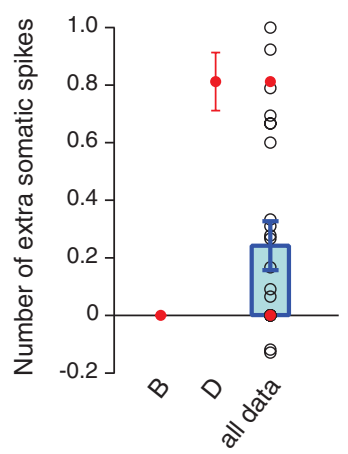

Figure 3. Dendritic spikes have only a weak influence on the somatic complex spike triggered by $C F$ stimulation. $A$, Recording configuration of experiment. The dendritic recording electrode was $80 \mu \mathrm{m}$ from the soma. $\boldsymbol{B}$, Multiple superimposed (F responses recorded at the soma (bottom) and dendrite (top) of the cell in $\boldsymbol{A}$. Left, Responses with one dendritic spike (4 sweeps); right, responses with two dendritic spikes ( 5 sweeps). Note that in this example, somatic spiking is the same regardless of the number of dendritic spikes, and that the second dendritic spike only produces a small response at the soma. C, A second example in which dendritic spikes have a stronger effect on the soma. The dendritic recording electrode was $125 \mu \mathrm{m}$ from the soma. $\boldsymbol{D}$, Threshold for a second dendritic spike occurred when a somatic holding current of $-160 \mathrm{pA}$ was applied (left: 1 spike, 29 sweeps; right: 2 spikes, 32 sweeps). In some (F responses, a second dendritic spike triggered an additional somatic spike ( $0.81 \pm 0.10$ spike added). Responses in which the second dendritic spike occurred $<2 \mathrm{~ms}$ after a somatic spike are shown in red; in these cases, either no further somatic spike or only a small somatic spikelet occurred. $\boldsymbol{E}$, Average number of somatic spikelets triggered by an extra dendritic spike. "B," "D," Mean \pm SD of the data shown in $\boldsymbol{B}$ and $\boldsymbol{D}$; "all data," averages from individual datasets (circles) and weighted mean \pm SEM of all datasets $(n=21$; bar). 0 n average, $0.24 \pm 0.09$ additional somatic spikes (significantly different from $0, p<0.01$ ) were triggered by an extra dendritic spike. Calibration in $\boldsymbol{D}$ also applies to $\boldsymbol{B}$.

$80-325 \mathrm{nS} ; n=40$ cells), comparable with the conductance values estimated using somatic voltage-clamp recording of CF EPSCs [200 \pm 23 nS; $n=16$ (Silver et al., 1998); $p=0.63$ ]. Decreasing the synaptic conductance from the optimal value reduced the number of evoked spikes in the complex spike, whereas increasing the conductance ultimately led to inactivation of spiking, associated with voltage ripples on top of an envelope of depolarization. This depolarization rarely exceeded $-30 \mathrm{mV}$, even at conductance values of $500 \mathrm{nS}$, thus maintaining a driving force for the synaptic conductance. The "optimal" synaptic conductance produced a highly quantitative match to the physiological complex spike in the same cells, with the number of spikes being indistinguishable $(3.1 \pm 0.12$ vs $3.1 \pm 0.12$ spikes; $n=40$ cells; $p=0.62$; paired $t$ test) between physiological and synthetic complex spikes. Furthermore, details of the spike waveform could also be closely matched, with amplitudes of individual spikelets being matched with an average error of only $18.0 \pm 2.0 \%$, and spike times matched with only $14.0 \pm 1.5 \%$ error $(n=40)$.

Together, these observations demonstrate that the distribution of the CF synaptic conductance across the dendrites is not necessary to permit burst firing or to maintain synaptic driving force, because the complex spike can be reproduced simply by concentrating a similar synaptic conductance at the soma.

\section{Dendritic spikes are not necessary for generating a complex spike}

In some cell types, bursts of spikes at the soma are triggered by activation of dendritic calcium spikes (Larkum et al., 1999; Magee and Carruth, 1999; Williams and Stuart, 1999). Physiological CF input typically triggers one to three dendritic calcium spikes (Fujita, 1968; Llinás and Sugimori, 1980b; Crepel et al., 1981). It is not clear whether these dendritic spikes are necessary to generate complex spikes. To address this question, we made simultaneous dendritic recordings (104 $\pm 6 \mu \mathrm{m}$ from the soma; range, 60-135 $\mu \mathrm{m}$ ) during the "optimal" somatic dynamic clamp for mimicking the physiological complex spike (Fig. 2A). Activation of the CF produced rapidly rising, large-amplitude dendritic calcium spikes during the somatic complex spike (Fig. 2 B) (Llinás and Sugimori, 1980b; Crepel et al., 1981). However, the somatic dynamic-clamp input that mimicked the complex spike in the same cell was not associated with generation of dendritic calcium spikes (Fig. 2C) (13 of 13 cells): only a small, slow dendritic depolarization was observed (Fig. 2D) (peak amplitude, $4.6 \pm 0.5$ $\mathrm{mV}$ vs $40.2 \pm 1.2 \mathrm{mV}$ for the physiological CF input; $p<10^{-12}$; peak $\mathrm{dV} / \mathrm{d} t=6.3 \pm 0.4 \mathrm{mV} / \mathrm{ms}$ vs $60.2 \pm 4.4 \mathrm{mV} / \mathrm{ms}$ for the physiological CF input; $p<10^{-7}$ ), reflecting the passive backpropagation of the somatic activity. 
A

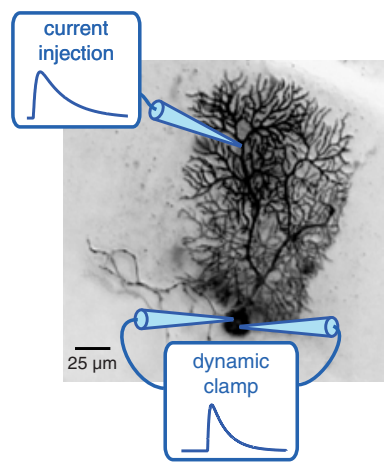

B

\section{1 dendritic spike $\quad 2$ dendritic spikes}
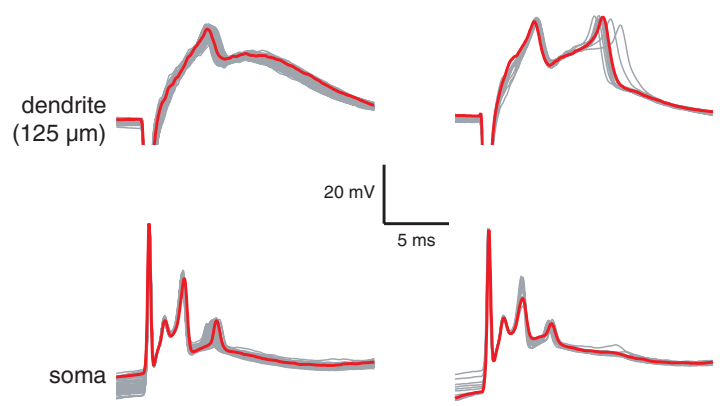

C

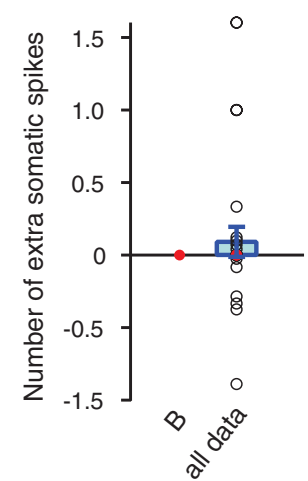

Figure 4. Dendritic spikes have only a weak influence on the somatic complex spike triggered by somatic dynamic clamp. $A$, Illustration of the experiment; during two-electrode dynamic-clamp injection of synaptic-like conductance $\left(\tau_{\text {rise }}=0.3 \mathrm{~ms} ; \tau_{\text {decay }}=3 \mathrm{~ms}\right.$ ) to the soma, dendritic current at threshold for triggering a second dendritic spike was injected (biexponential of $\tau_{\text {rise }} 0.5 \mathrm{~ms}$ and $\tau_{\text {decay }} 5 \mathrm{~ms}$, together with tonic depolarizing current). $\boldsymbol{B}$, Responses of Purkinje cell ( $\left.\boldsymbol{A}\right)$ to a somatic synaptic-like conductance ( $200 \mathrm{nS}$ ) and a simultaneous biexponential dendritic current ( $3 \mathrm{nA}$ ). Tonic current injection $(80 \mathrm{pA})$ to the dendrite $(125 \mu \mathrm{m})$ took the cell to threshold for generating a second dendritic calcium spike. The layout is as in Figure $3 B$. The second dendritic spike (right-hand column) triggered no further somatic spikelets. C, Average number of somatic spikelets triggered by an extra dendritic spike during somatic dynamic clamp. "B," Mean \pm SD of the data shown in

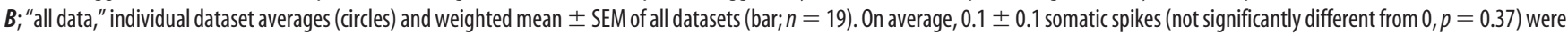
triggered by an extra dendritic spike.

\section{Contribution of dendritic calcium spikes to somatic output during the complex spike}

These dendritic recordings have demonstrated that the somatic complex spike can be generated independently of a dendritic calcium spike, i.e., that dendritic calcium spikes are not necessary for complex spike generation. How then do dendritic calcium spikes contribute to the complex spike? We addressed this question by taking advantage of the stochastic nature of spike generation at threshold, where, by setting the tonic current injection at the appropriate value, the dendritic CF response could alternate by chance between one and two (or sometimes between two and three) dendritic spikes. In this way, the effect of adding a dendritic calcium spike on the somatic complex spike could be assessed. Using this approach, we found that an extra dendritic calcium spike had a remarkably small effect on the somatic complex spike waveform. Two examples are shown in Figure 3. In the Purkinje cell shown in Figure $3 A$, the addition of a second dendritic calcium spike did not produce any additional spikelets in the somatic complex spike, only a small additional depolarization $(\sim 5 \mathrm{mV})$ after the last spikelet (Fig. $3 B)$. In contrast, in the Purkinje cell shown in Figure 3C, an extra dendritic calcium spike could, in some trials, trigger an additional spikelet in the somatic complex spike (Fig. $3 D$ ). On average, $0.81 \pm 0.10$ additional somatic spikes were induced by the extra dendritic calcium spike in this neuron (Fig. $3 E)\left(p<10^{-6}\right)$. Thus, even in a cell in which a calcium spike had relatively strong effects, it added less than one spike on average to the somatic complex spike. Across the population of cells, an extra dendritic calcium spike triggered only $0.24 \pm 0.09$ additional spikes at the soma (Fig. 3E) (weighted mean \pm SEM; $n=21 ; p<0.01$ ), and of these we predict (Monsivais et al., 2005) that only $\sim 25 \%$ might propagate down the axon. The strength of the effect of an extra dendritic spike was not dependent on age (P18-P24, $r=0.05 ; p=0.82)$ or on dendritic recording distance (range $=60-155 \mu \mathrm{m} ; r=0.2 ; p=0.37$ ).

We performed an additional set of experiments to investigate the influence of the distributed synaptic conductance on the propagation of the dendritic spike to the soma. During somatic dynamic-clamp experiments, which we demonstrate above can mimic a complex spike, we "added" varying numbers of dendritic spikes at threshold by injecting current via a dendritic recording electrode (Fig. 4A, B). The dendritic spikes triggered in this way had a similar, but even weaker effect than physiologically triggered dendritic spikes; adding a single dendritic spike triggered only $0.1 \pm 0.1$ additional spikelets in the somatic complex spike (Fig. 4C) (not significantly different; $n=19 ; p=0.37$ ). This indicates that the influence of dendritic spikes on somatic spiking is weak even when the CF synaptic conductance is not widely distributed in the dendritic tree, along the path of propagation.

Together, these experiments directly demonstrate that dendritic calcium spikes have only a weak effect on the somatic complex spike, and are not responsible for producing the somatic burst of spikes.

Determinants of dendritic spike influence on somatic spiking Why is the dendritic calcium spike so ineffective in triggering somatic spikelets? There are several reasons for this. First, dendritic spikes in Purkinje cells are relatively small and brief. We estimated the amplitude of dendritic spikes triggered by CF input relative to just-subthreshold events on alternating trials (Fig. $5 \mathrm{~A}$ ), giving a mean peak amplitude of only $10.6 \pm 1.4 \mathrm{mV}$, and a half-width of $1.6 \pm 0.12 \mathrm{~ms}$ (dendritic recording at $115 \pm 11 \mu \mathrm{m}$ from the soma; $n=9$ ). Second, dendritic spikes experience substantial attenuation between the dendrite and the soma. Dendritic spikes were attenuated to $34.5 \pm 4.6 \%$ of their original amplitude by the time they reached the soma (Fig. $5 A, B)(n=9$; dendritic spikes measured at $115 \pm 11 \mu \mathrm{m}$ from the soma; note that this measure provides an upper limit of the degree of attenuation at this distance during a complex spike, because we rejected the occasional events that triggered somatic spikes). Third, dendritic spikes often arrived at the soma within the apparent refractory period for somatic spikes. When the dendritic spike occurred $<0.8 \mathrm{~ms}$ after a preceding somatic spikelet, no additional somatic spikelet was triggered. Furthermore, although later dendritic spikes could successfully trigger somatic spikelets, there was a sigmoidal relationship between the amplitude of these somatic spikelets and the latency of the dendritic spike (as measured in Fig. 5C). This was observed both within individual datasets (Fig. 5D; see also corresponding traces in Fig. $3 D$ ) and across 
all datasets (Fig. 5E), where the half-maximum of the relationship was at $1.4 \mathrm{~ms}$. However, even when the dendritic spike occurred well outside the apparent somatic refractory period, it was still often unable to trigger an additional somatic spikelet. This was because the somatic depolarization caused by the dendritic spike was below threshold for generating a somatic spikelet (weighted mean subthreshold depolarization, $4.1 \pm 0.8 \mathrm{mV}$ higher than previous trough vs spike threshold, $6.2 \pm 0.5 \mathrm{mV}$ higher; $n=7 ; p<0.03$, paired $t$ test). Dendritic spikes triggered during somatic dynamic clamp were similarly often found to be within a somatic refractory period (supplemental Fig. 2, available at www.jneurosci.org as supplemental material) or below spike threshold (mean subthreshold depolarization, $1.3 \pm 0.2 \mathrm{mV}$ vs spike threshold, $1.9 \pm 0.7 \mathrm{mV} ; n=6 ; p<0.04$, paired $t$ test).

This combination of characteristics explains why dendritic spikes have a relatively weak influence on somatic spikelet generation. As a consequence, there was no consistent temporal relationship between a dendritic spike and somatic spikelets. Specifically, the peaks of individual dendritic spikes could either occur both before or after a somatic complex spikelet it appeared to promote (supplemental Fig. 3A, available at www.jneurosci.org as supplemental material). This indicates that somatic spikelets are not simply reflections of forwardpropagated dendritic spikes. In fact, the timing of extra somatic spike appears to be strongly influenced by intrinsic axosomatic properties. The later a dendritic spike occurs after the penultimate somatic spike, the earlier the extra spike occurs relative to the dendritic spike (supplemental Fig. 3B, available at www. jneurosci.org as supplemental material). If the somatic ISI was independent of the dendritic spike time, the slope of this relationship would be -1 (conversely, if it was entirely dependent on the dendritic spike time, the slope would be $0)$ : we find a slope of -0.54 , indicating that the somatic spike timing was influenced, but not strictly determined, by the dendritic spike time.

\section{Dendritic spikes triggered by the CF modulate pauses in Purkinje cell output} We have demonstrated that dendritic spikes evoked by CF input have a remarkably weak electrical effect on the somatic complex spike waveform, and thus on the number of spikes transmitted down the axon directly associated with the complex spike. CF activation is also associated with a pause in spontaneous spiking after the complex spike in vivo (Latham and Paul, 1970; Bloedel and Roberts, 1971; Armstrong and Rawson, 1979; Sato et al., 1992). The mechanisms underlying the generation and duration of this pause are not well understood. Armstrong and Rawson (1979) found
A
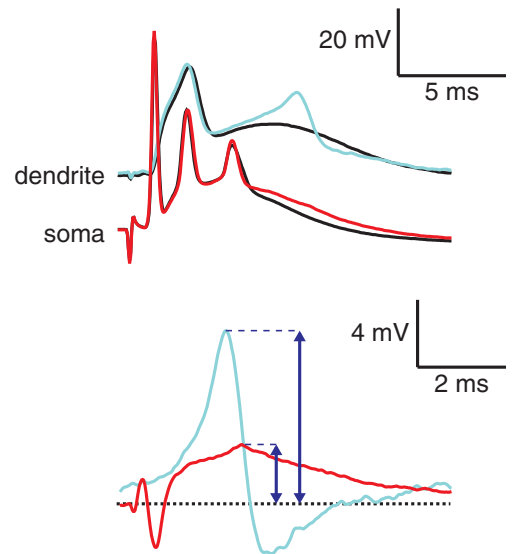

C

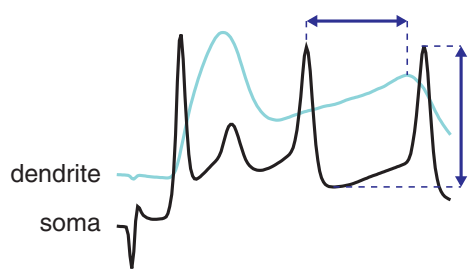

B

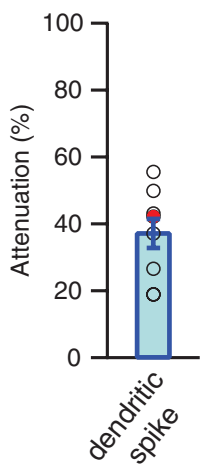

E

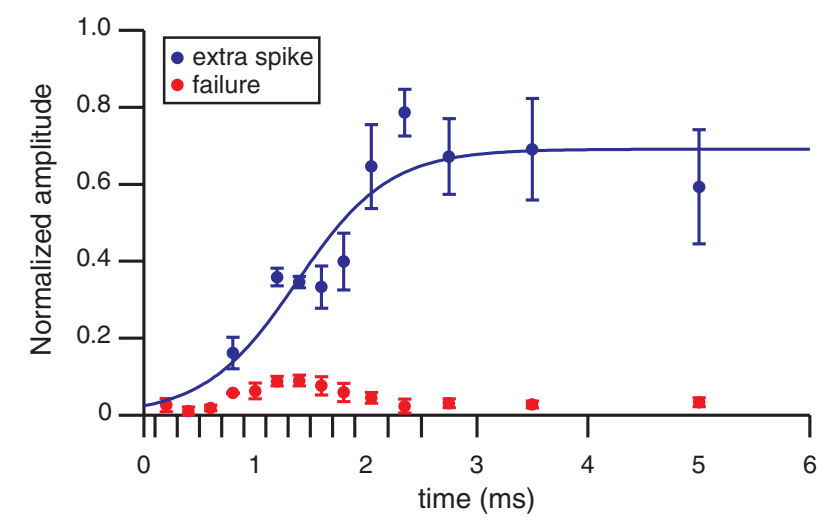

Figure 5. Dendritic spikes are highly attenuated and often occur within the somatic refractory period. $\boldsymbol{A}$, Method used to measure attenuation of dendritic spikes during the complex spike. Top, Example response with an extra dendritic spike, recorded simultaneously in the dendrite (light blue; $142 \mu \mathrm{m}$ from soma) and soma (red; traces offsetfor clarity); also shown are dendritic and somatic averages of events without extra dendritic spikes but with similar somatic firing pattern (black). Bottom, Subtraction of these averages from the sweeps with extra spikes reveals the depolarization in the dendrite (light blue) and the soma (red) caused by the extra dendritic spike. The peak differences in depolarization were measured (blue arrows) at both locations, and attenuation was calculated as somatic depolarization as a percentage of dendritic depolarization. $\boldsymbol{B}$, Attenuation of extra dendritic spikes in individual datasets (open symbols; red symbol indicates data shown in $A$ ) and in the whole population (blue bar; mean \pm SEM). $C$, Illustration of the measurements made of dendritic spike time and resulting somatic event amplitude. Horizontal arrow, Time between the extra dendritic spike and the spike preceding the somatic event. Vertical arrow, Somatic event amplitude, measured as difference between preceding trough minimum and event maximum; this amplitude is normalized by the amplitude (above average baseline $V_{m}$ ) of the first spike of the complex spike. $D$, Dependence of somatic event amplitude on dendritic spike latency, as illustrated in C, for the data shown in Figure 3D. Red circles, Cases in which an extra dendritic spike failed to trigger a spike, generating only a subthreshold depolarization; blue circles, cases in which an extra spike triggered a somatic spike. The refractory trend is highlighted by a sigmoidal fit (black line); haff-maximum $=1.7 \mathrm{~ms}$.E, Dependence of somatic event amplitude on dendritic spike latency ( $n=19$ datasets), binned according to the time intervals marked by the $x$-axis ticks. Red and blue symbols are as in $\boldsymbol{D}$. The refractory trend is highlighted by a sigmoidal fit to extra spike data, constrained to a baseline amplitude of 0 ; half-maximum $=1.4 \mathrm{~ms}$. 
A dendrite
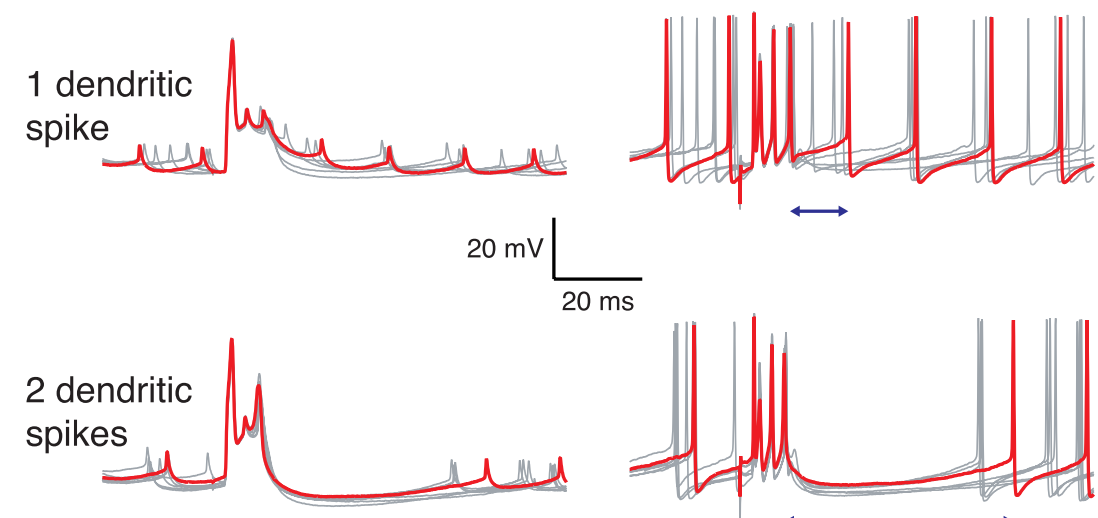

B

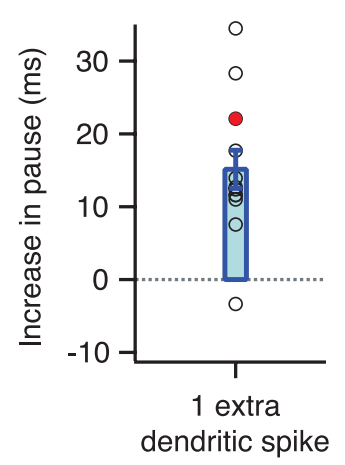

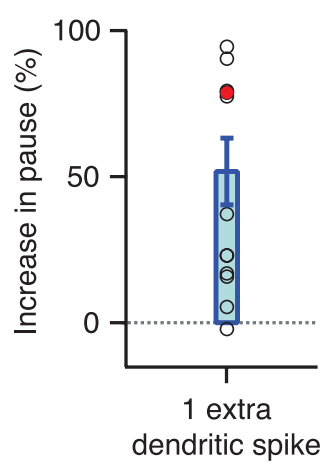

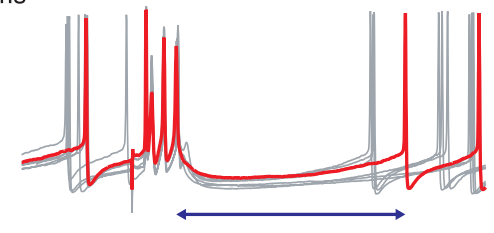

C
Figure 6. Dendritic calcium spikes regulate the post-complex spike pause. $\boldsymbol{A}$, Example of data collected at threshold for generating a second dendritic calcium spike in response to (F stimulation (grouped according to the number of dendritic spikes), on a time scale that shows the post-complex spike pause. Top, One dendritic spike; bottom, two dendritic spikes; left, dendritic recordings ( $60 \mu \mathrm{m}$ from the soma); right, somatic recordings. Arrows indicate pause duration (time between the last spikelets in the complex spike and the next spontaneous spike) measured in the red example sweeps. An extra dendritic spike increased the pause from $28.0 \pm 17.9$ to $50.0 \pm 12.7 \mathrm{~ms}(p<0.01) . \boldsymbol{B}$, Average increase in pause duration triggered by an extra dendritic calcium spike (in milliseconds). Symbols show averages of individual datasets (dataset shown in $\boldsymbol{A}$ highlighted in red); bar indicates weighted mean \pm SEM of the population data ( $n=11$; significantly different from $0, p<0.0005$ ). $C$, Average increase in pause duration triggered by an extra dendritic calcium spike (as a percentage of pause duration without extra dendritic calcium spike). Symbols and bars are as in $\boldsymbol{B}(n=15$; significantly different from $0, p<0.005)$.

that pause length in vivo depends on the spontaneous simple spike firing rate, and we found this to hold true in vitro. Only at fairly low spontaneous firing rates $(>20-25 \mathrm{~ms}$ ISI) did the length of the pause exceed one spontaneous ISI (data not shown). Furthermore, by examining our somatic and dendritic recordings, we found that the duration of the pause also strongly depends on the number of dendritic calcium spikes triggered by $\mathrm{CF}$ input (Fig. 6A). An extra dendritic spike lengthened the postcomplex spike pause by $15.2 \pm 2.6 \mathrm{~ms}$ (Fig. 6B) (weighted mean \pm SEM; $p<0.001$ ), representing a $52 \pm 11 \%$ (Fig. $6 C$ ) increase in pause duration, or a further $0.56 \pm 14$ ISIs quiescence before spontaneous spiking resumed. The effect of the extra dendritic spike on the pause was independent of the number of extra spikelets added to the somatic complex spike $(r=0.36 ; p=0.30)$, and was also independent of the spontaneous firing rate $(r=$ $-0.35 ; p=0.29)$. The effect of dendritic spikes on the post- complex spike pause was also assessed by comparing CF-evoked events to those generated by somatic dynamic clamp, and so lacking dendritic spikes (supplemental Fig. $4 A$, available at www.jneurosci.org as supplemental material). The pause after climbing fiber input that evoked only one dendritic spike was, on average, $3.8 \pm 1.6$ ms longer than that after the matching dynamic-clamp-evoked complex spikes, which did not evoke a dendritic spike $(p<$ $0.05 ; n=11$ ) (supplemental Fig. $4 B$, available at www.jneurosci.org as supplemental material), corresponding to a $31 \pm 12 \%$ increase in pause duration, or a further $0.22 \pm 0.09$ ISIs (supplemental Fig. 4C, available at www.jneurosci.org as supplemental material).

One way in which dendritic calcium spikes might influence the post-complex spike pause is through activation of hyperpolarizing conductances (e.g., calciumactivated potassium channels). We therefore measured the amplitude of postcomplex spike AHPs (Fig. 7A). A second dendritic spike increased dendritic AHPs by $3.4 \pm 0.7 \mathrm{mV}$ (Fig. $7 B, C$ ) (weighted mean \pm SEM; $p<0.001)$; a similar change in somatic AHPs was also seen. Pause duration was correlated with the amplitude of the dendritic AHP across all datasets (Fig. $7 D)\left(n=11 ; r=-0.89 ; p<10^{-16}\right)$, and an extra dendritic spike caused both larger AHPs and longer pauses.

These data suggest that, from the point of view of the postsynaptic deep cerebellar nuclei (DCN) neurons, the most salient effect of dendritic spikes may be to increase the pause after the complex spike rather than the number and timing of spikelets in the complex spike itself.

\section{Axonal origin of somatic complex spikes} The results described above show that dendritic spikes are not directly linked to the spikelets in the complex spike. By elimination, the spikelets must therefore arise either in the soma or in the axon. This is important to discriminate, given that the powerful CF input is almost exclusively dendritic. To resolve this question, we made simultaneous cell-attached recordings from the soma and proximal axon of Purkinje cells ( $\leq 75 \mu \mathrm{m}$ from the soma) while evoking CF input. This enabled us to directly compare the relative timing at the soma and axon of each spikelet component of the complex spike. In all cases, the spikelets occurred first in the axon (Fig. 8). When somatic and axonal spikes were averaged by triggering off the somatic spike, the axonal spike preceded the somatic spike for all spikelets, by $0.03 \pm 0.01 \mathrm{~ms}(n=8$ cells $), 0.15 \pm 0.04 \mathrm{~ms}(n=7), 0.14 \pm 0.03$ $\mathrm{ms}(n=5)$, and $0.14 \pm 0.03 \mathrm{~ms}(n=5)$ for the first, second, third, and fourth spikelets in the complex spike, respectively. The fact that the axonal spike precedes the somatic spike in each case indicates that all the spikelets within the complex spike are initiated in the axon. 


\section{Discussion}

Our results provide direct evidence that all spikelets within the complex spike of Purkinje cells originate in the axon. The prominent dendritic spikes triggered by CF activation play only a very minor and indirect role in the generation of this stereotyped axonal burst. Dendritic spikes propagate poorly to the soma, where they were often below spike threshold or within the refractory period, and thus usually failed to trigger an additional axosomatic spike. Consistent with these findings, we found that a distributed pattern of dendritic synaptic input, although required for triggering dendritic calcium spikes, is not necessary for generation of the complex spike burst. These results support a model of the Purkinje cell in which the dendrites are functionally separate from the axon and soma during the complex spike. We identify a new role for dendritic spikes as regulators of the post-complex spike pause, complementing their roles as local triggers for synaptic plasticity and modulators of intrinsic firing.

\section{Axonal initiation of the complex spike}

Our paired recordings from the soma and axon resolve the question of the origin of the complex spike (Schmolesky et al., 2002) by directly demonstrating that all the spikelets are initiated in the axon, similarly to spontaneous simple spikes (Stuart and Häusser, 1994; Clark et al., 2005). The axonal origin of the spikelets is surprising, given the enormous CF-triggered current concentrated in the soma and proximal dendrites. In other neurons, although the lowest-threshold site for initiation of sodium action potentials is typically in the axon (Coombs et al., 1957; Colbert and Johnston, 1996; Palmer and Stuart, 2006), strong synaptic input can shift the initiation site from the axon to the dendrites (Mainen et al., 1995; Chen et al., 1997; Stuart et al., 1997; Golding and Spruston, 1998). In Purkinje cells, however, dendrites are unable to support initiation or active backpropagation of sodium spikes, because of their low $\mathrm{Na}^{+}$channel density (Stuart and Häusser, 1994), and their elaborate geometry (Vetter et al., 2001; Bekkers and Häusser, 2007). In contrast, the axon is more favorable for spike initiation because it is protected from the substantial capacitive load of the soma and dendrites by its high axial resistance (Dodge and Cooley, 1973; Mainen et al., 1995; Colbert and Pan, 2002), potentially aided by increased densities or altered properties of axonal $\mathrm{Na}^{+}$ channels (Mainen et al., 1995; Colbert and Pan, 2002; Boiko et al., 2003; Kole et al., 2008). The next step will be to identify the precise location of the initiation site of the complex spike within the axon.

A

$B$
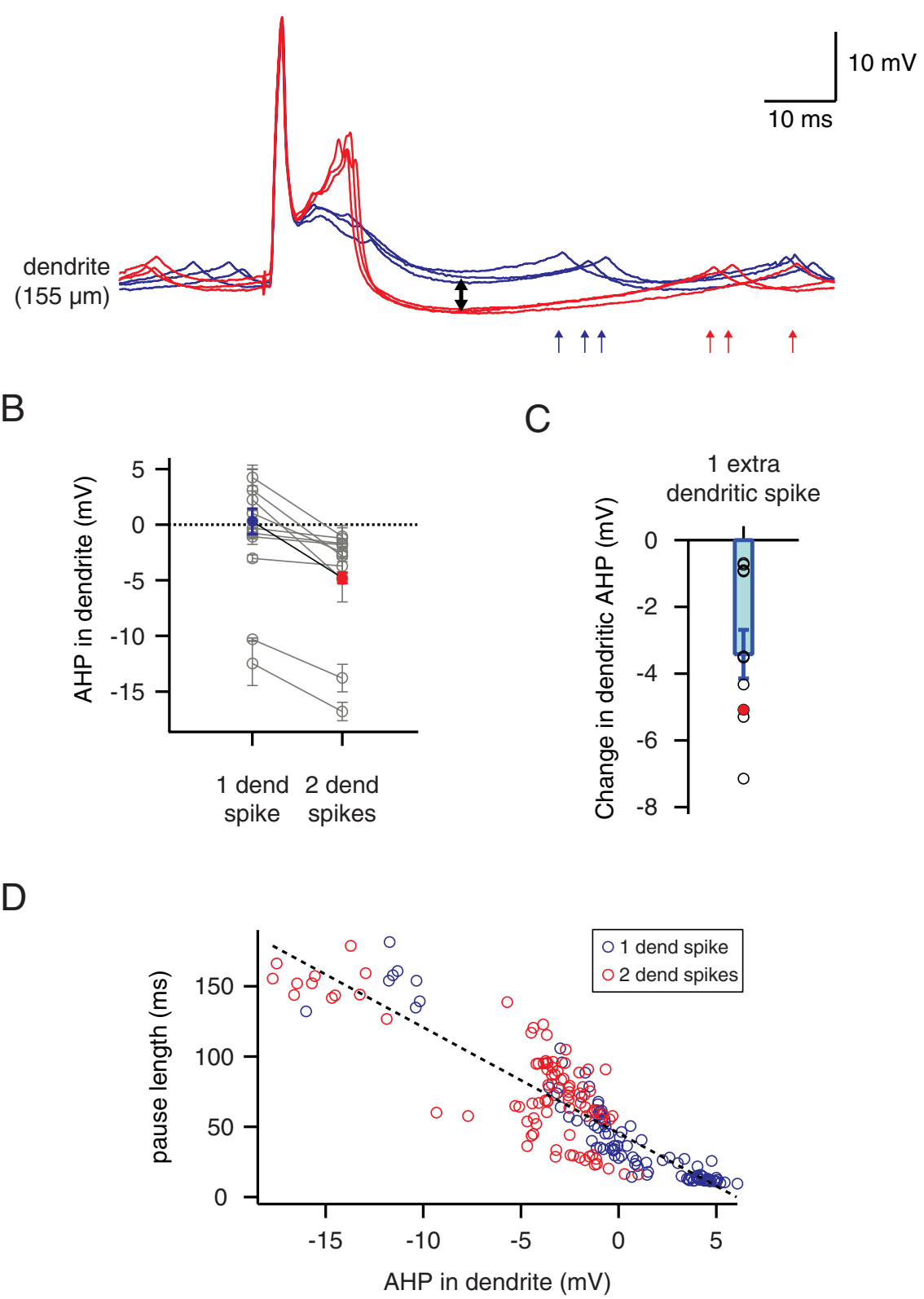

Figure 7. Dendritic spikes regulate the AHP after the complex spike. $\boldsymbol{A}$, Dendritic recording (155 $\mu \mathrm{m}$ from the soma) of responses to CF stimulation collected at threshold for generating a second dendritic calcium spike (blue, 1 dendritic spike; red, 2 dendritic spikes). The black arrow indicates the measured difference in AHP amplitude; red and blue arrows mark the time of somatic action potentials (reflected as small depolarizations in the dendritic recording) that terminate the post-complex spike pause in the one- and two-dendritic-spike traces, respectively. $\boldsymbol{B}$, Average dendritic AHP (minimum dendritic membrane potential reached during the pause minus average baseline dendritic membrane potential preceding (F stimulation) after (F stimulation that evokes, at threshold, one or two dendritic calcium spikes. Lines connect one- and two-spike data from the same set; the dataset shown in $A$ is highlighted in color. $C$, Average change in AHP amplitude caused by an extra dendritic spike. Circles show averages of individual datasets (dataset shown in $\boldsymbol{A}$ highlighted in red); bar indicates weighted mean \pm SEM of the population data ( $n=11$; significantly different from $0, p<0.001$ ). $\boldsymbol{D}$, Relationship between post-complex spike pause duration and dendritic AHP amplitude. Each data point represents a single measurement made after CF stimulation at threshold for generating an extra dendritic spike ( $n=11$ cells; blue symbols, 1 dendritic spike; red symbols, 2 dendritic spikes). The black line indicates the negative correlation between pause length and AHP depth $\left(r=-0.89 ; p<10^{-16}\right)$. dend, Dendritic.

\section{Somatic dynamic clamp reproduces the complex spike}

By mimicking the complex spike waveform with a somatic synapticlike conductance, we have shown that neither dendritic spikes nor a dendritic distribution of synaptic conductance is required for complex spike generation. Surprisingly, the shunt produced by concentrating the entire synaptic conductance at the soma does not prevent 
A

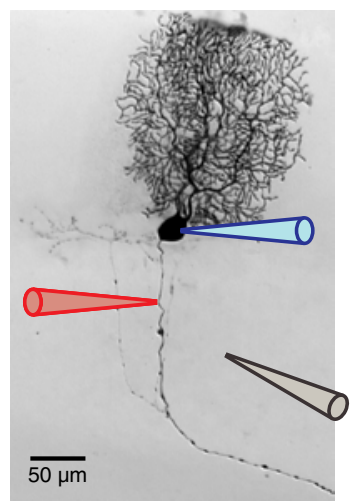

B

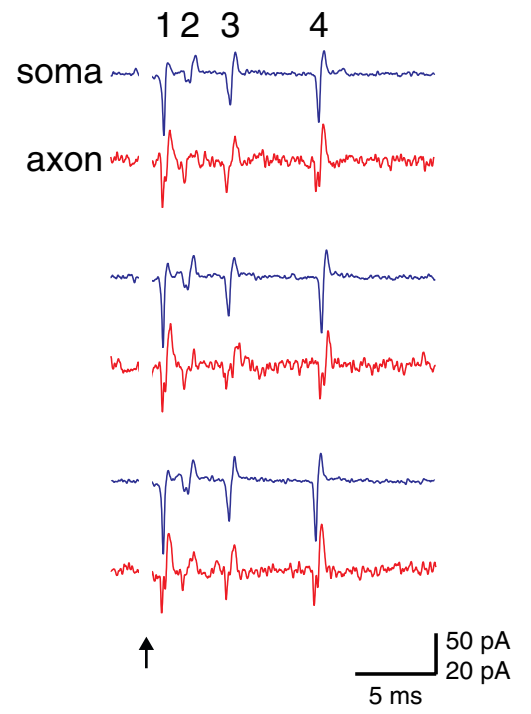

C

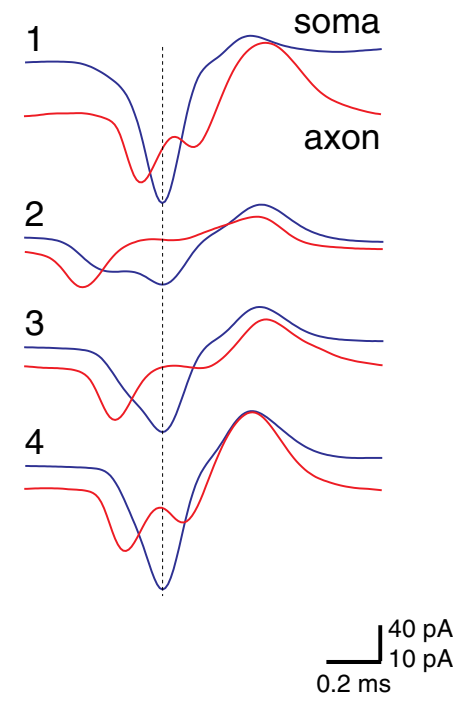

Figure 8. All spikelets of the complex spike originate in the axon. $A$, Biocytin-filled Purkinje cell indicating the location of the somatic (blue) and axonal (red) recording electrodes for the data shown in $\boldsymbol{B}$ and $\boldsymbol{C}$. The axonal electrode was located at $55 \mu \mathrm{m}$ from the soma. The $(F$ stimulation electrode is also illustrated (gray). $\boldsymbol{B}$, Simultaneous cell-attached recordings made from the soma and axon during (F stimulation (arrow), which generates a complex spike with four spikelets. C, Averages for each spikelet of the complex spike generated by aligning data to the peak of the somatic capacitive current, indicated by the dotted line.

the complex spike burst, generating spiking similar to the rapid bursts produced by somatic current injection (Callaway and Ross, 1997; Swensen and Bean, 2003; McKay et al., 2005). This is due in part to the axonal initiation site of spikelets, which provides electrical isolation from the somatic shunt. Furthermore, the powerful and fast somatic voltage-gated $\mathrm{Na}^{+}$conductances in Purkinje cells ( $\mathrm{Ra}$ man and Bean, 1999), together with the $\mathrm{K}^{+}$conductances (Raman and Bean, 1999; Edgerton and Reinhart, 2003; Martina et al., 2003; McKay and Turner, 2004; Zagha et al., 2008), which balance large depolarizing currents (Swensen and Bean, 2005; Zagha et al., 2008) and help maintain high-frequency firing, appear to predominate over the synaptic conductance during complex spike generation.

\section{Propagation of dendritic spikes}

We demonstrate that the dendritic spikes triggered by CF input do not directly trigger somatic spikelets in the complex spike and influence its generation only weakly. This parallels the relatively weak effect of dendritic inhibition on the somatic complex spike (Callaway et al., 1995). We show that the low efficacy of dendritic spikes in Purkinje neurons is attributable to a combination of factors. First, they are relatively brief and small, in striking contrast to the $\sim 80 \mathrm{mV}, \sim 60 \mathrm{~ms}$ dendritic calcium spikes in layer 5 pyramidal cells (Zhu, 2000). Furthermore, their dendrosomatic propagation is substantially attenuated, attributable in part to the unfavorable impedance mismatches of the highly branching geometry of the Purkinje cell dendritic tree (Vetter et al., 2001), and they may be further diminished by somatic active shunting conductances (Häusser et al., 2001). In addition, the strong synaptic and voltage-gated dendritic conductances active during the complex spike, although initially triggering dendritic spikes, may serve to restrict their spread, reducing the current transmitted to the soma. However, dendritic spikes generated in the absence of distributed dendritic conductance are attenuated to a similar or even greater extent (Fig. 4) (Rancz and Häusser, 2006), suggesting that widespread dendritic spike initiation during the complex spike may actually aid propagation to the soma by reducing the axial current between branches and thus partially mitigating the impedance mismatch. Finally, we demonstrate that the highly attenuated dendritic spike is usually subthreshold when it reaches the soma, or within the refractory period of the previous spikelet. Together, these factors explain why dendritic spikes in Purkinje cells, consistent with previous work (Callaway et al., 1995), have a far weaker influence on axonal spiking than in mitral neurons (Chen et al., 1997), or in cortical and hippocampal pyramidal neurons (Schiller et al., 1997; Golding and Spruston, 1998; Larkum et al., 1999), in which a dendritic calcium spike can contribute up to 2.5 output spikes (Williams and Stuart, 2002).

\section{Functional role of dendritic spikes triggered by CF input}

We have demonstrated a new functional role for dendritic spikes in Purkinje cells: regulation of the pause in axonal output after the complex spike. This pause is a well known feature of the CF response in vivo (Latham and Paul, 1970; Bloedel and Roberts, 1971; Armstrong and Rawson, 1979; Sato et al., 1992; Barmack and Yakhnitsa, 2008), but its underlying mechanisms are unknown. Our findings suggest that the calcium entry associated with CF-triggered dendritic spikes (Ross and Werman, 1987; Miyakawa et al., 1992) activates calcium-dependent potassium conductances (Hounsgaard and Midtgaard, 1989; Edgerton and

Reinhart, 2003; Rancz and Häusser, 2006), causing hyperpolarization and a prolonged pause before resumption of spontaneous firing, analogous to the recently described pause in spiking triggered by strong parallel fiber input (Steuber et al., 2007). This suggestion is further supported by the finding that disruption of Purkinje cell calcium buffering (Servais et al., 2005) alters postcomplex spike pause duration. Thus, pause duration reports the number of dendritic spikes triggered by CF input. The pause is likely to be a potent signal to downstream DCN neurons [perhaps more so than the complex spike itself, which is often poorly propagated down the axon (Khaliq and Raman, 2005; Monsivais et al., 2005)], given that the relief of DCN cells from persistent inhibi- 
tion triggers rebound firing (Aizenman and Linden, 1999; McKay et al., 2005), which is both a salient electrical signal and a trigger for plasticity at the DCN (Nelson et al., 2003; Pugh and Raman, 2006).

This new role for dendritic spikes in regulating the postcomplex spike pause complements the well established functions linked to the large dendritic calcium influx they generate (Ross and Werman, 1987; Miyakawa et al., 1992). This biochemical signal can trigger long-term depression of CF input and plays an important role in short-term and long-term regulation of parallel fiber and inhibitory synaptic strength (Hansel et al., 2001; Brenowitz and Regehr, 2005). CF activity also regulates intrinsic firing behaviors in ways likely to involve calcium influx, such as modulating spontaneous firing rate and pattern (Cerminara and Rawson, 2004; McKay et al., 2007).

\section{A new perspective on Purkinje cell function}

The CF input to the Purkinje cell provides a timing signal for online motor control (Welsh and Llinás, 1997; Kitazawa et al., 1998) and an error signal, which enables synaptic plasticity at parallel fiber synapses and mossy fiber-DCN synapses (Gilbert and Thach, 1977; Kitazawa et al., 1998; Pugh and Raman, 2006). We demonstrate that CF input briefly divides the Purkinje cell into two weakly coupled functional compartments, a dendritic and an axosomatic compartment, which reflect these distinct roles. By distributing CF input in the dendrites, synaptic and active dendritic currents are efficiently isolated from the shunt of the Purkinje cell's specialized high-frequency firing mechanisms (Stuart and Häusser, 1994; Raman and Bean, 1999; Häusser et al., 2001). This allows dendritic spike generation and the associated, plasticity-triggering calcium influx to occur in parallel with burst generation at the soma. The mutual isolation of the two compartments allows the number of dendritic calcium spikes, and the resulting downstream dendritic effects of CF input, to be modulated by parallel fiber or inhibitory input without strongly influencing the burst pattern at the soma (Callaway et al., 1995). In contrast, the regulation of the post-complex spike pause by dendritic spikes triggered by the CF input reveals a new link between plasticity in the Purkinje cell dendritic tree, Purkinje cell output pattern, and the resulting plasticity at downstream targets.

\section{References}

Aizenman CD, Linden DJ (1999) Regulation of the rebound depolarization and spontaneous firing patterns of deep nuclear neurons in slices of rat cerebellum. J Neurophysiol 82:1697-1709.

Ariav G, Polsky A, Schiller J (2003) Submillisecond precision of the inputoutput transformation function mediated by fast sodium dendritic spikes in basal dendrites of CA1 pyramidal neurons. J Neurosci 23:7750-7758.

Armstrong DM, Rawson JA (1979) Activity patterns of cerebellar cortical neurones and climbing fibre afferents in the awake cat. J Physiol 289:425-448.

Barmack NH, Yakhnitsa V (2008) Functions of interneurons in mouse cerebellum. J Neurosci 28:1140-1152.

Bekkers JM, Häusser M (2007) Targeted dendrotomy reveals active and passive contributions of the dendritic tree to synaptic integration and neuronal output. Proc Natl Acad Sci U S A 104:11447-11452.

Bland JM, Kerry SM (1998) Statistics notes. Weighted comparison of means. BMJ 316:129.

Bloedel JR, Roberts WJ (1971) Action of climbing fibers in cerebellar cortex of the cat. J Neurophysiol 34:17-31.

Boiko T, Van Wart A, Caldwell JH, Levinson SR, Trimmer JS, Matthews G (2003) Functional specialization of the axon initial segment by isoformspecific sodium channel targeting. J Neurosci 23:2306-2313.

Brenowitz SD, Regehr WG (2005) Associative short-term synaptic plasticity mediated by endocannabinoids. Neuron 45:419-431.

Callaway JC, Ross WN (1997) Spatial distribution of synaptically activated sodium concentration changes in cerebellar Purkinje neurons. J Neurophysiol 77:145-152.

Callaway JC, Lasser-Ross N, Ross WN (1995) IPSPs strongly inhibit climbing fiber-activated $\left[\mathrm{Ca}^{2+}\right] \mathrm{i}$ increases in the dendrites of cerebellar Purkinje neurons. J Neurosci 15:2777-2787.

Campbell NC, Ekerot CF, Hesslow G (1983) Interaction between responses in Purkinje cells evoked by climbing fibre impulses and parallel fibre volleys in the cat. J Physiol 340:225-238.

Cerminara NL, Rawson JA (2004) Evidence that climbing fibers control an intrinsic spike generator in cerebellar Purkinje cells. J Neurosci 24:4510-4517.

Chen WR, Midtgaard J, Shepherd GM (1997) Forward and backward propagation of dendritic impulses and their synaptic control in mitral cells. Science 278:463-467.

Clark BA, Monsivais P, Branco T, London M, Häusser M (2005) The site of action potential initiation in cerebellar Purkinje neurons. Nat Neurosci 8:137-139.

Colbert CM, Johnston D (1996) Axonal action-potential initiation and $\mathrm{Na}^{+}$channel densities in the soma and axon initial segment of subicular pyramidal neurons. J Neurosci 16:6676-6686.

Colbert CM, Pan E (2002) Ion channel properties underlying axonal action potential initiation in pyramidal neurons. Nat Neurosci 5:533-538.

Coombs JS, Curtis DR, Eccles JC (1957) The interpretation of spike potentials of motoneurones. J Physiol 139:198-231.

Crepel F, Dhanjal SS, Garthwaite J (1981) Morphological and electrophysiological characteristics of rat cerebellar slices maintained in vitro. J Physiol 316:127-138.

Davie JT, Kole MH, Letzkus JJ, Rancz EA, Spruston N, Stuart GJ, Häusser M (2006) Dendritic patch-clamp recording. Nat Protoc 1:1235-1247.

Dodge FA, Cooley JWJ (1973) Action potential of the motorneuron. IBM J Res Develop 17:219-229.

Doiron B, Laing C, Longtin A, Maler L (2002) Ghostbursting: a novel neuronal burst mechanism. J Comput Neurosci 12:5-25.

Eccles JC, Llinás R, Sasaki K (1966) The excitatory synaptic action of climbing fibres on the Purkinje cells of the cerebellum. J Physiol 182:268-296.

Edgerton JR, Reinhart PH (2003) Distinct contributions of small and large conductance $\mathrm{Ca} 2+$-activated $\mathrm{K}+$ channels to rat Purkinje neuron function. J Physiol 548:53-69.

Fujita Y (1968) Activity of dendrites of single Purkinje cells and its relationship to so-called inactivation response in rabbit cerebellum. J Neurophysiol 31:131-141.

Geiger JR, Bischofberger J, Vida I, Fröbe U, Pfitzinger S, Weber HJ, Haverkampf K, Jonas P (2002) Patch-clamp recording in brain slices with improved slicer technology. Pflugers Arch 443:491-501.

Gilbert PF, Thach WT (1977) Purkinje cell activity during motor learning. Brain Res 128:309-328.

Golding NL, Spruston N (1998) Dendritic sodium spikes are variable triggers of axonal action potentials in hippocampal CA1 pyramidal neurons. Neuron 21:1189-1200

Granit R, Phillips CG (1956) Excitatory and inhibitory processes acting upon individual Purkinje cells of the cerebellum in cats. J Physiol 133:520-547.

Hansel C, Linden DJ, D'Angelo E (2001) Beyond parallel fiber LTD: the diversity of synaptic and non-synaptic plasticity in the cerebellum. Nat Neurosci 4:467-475.

Häusser M, Major G, Stuart GJ (2001) Differential shunting of EPSPs by action potentials. Science 291:138-141.

Hounsgaard J, Midtgaard J (1989) Synaptic control of excitability in turtle cerebellar Purkinje cells. J Physiol 409:157-170.

Ito M (2001) Cerebellar long-term depression: characterization, signal transduction, and functional roles. Physiol Rev 81:1143-1195.

Khaliq ZM, Raman IM (2005) Axonal propagation of simple and complex spikes in cerebellar Purkinje neurons. J Neurosci 25:454-463.

Khaliq ZM, Raman IM (2006) Relative contributions of axonal and somatic $\mathrm{Na}$ channels to action potential initiation in cerebellar Purkinje neurons. J Neurosci 26:1935-1944.

Kitazawa S, Kimura T, Yin PB (1998) Cerebellar complex spikes encode both destinations and errors in arm movements. Nature 392:494-497.

Kole MH, Ilschner SU, Kampa BM, Williams SR, Ruben PC, Stuart GJ (2008) Action potential generation requires a high sodium channel density in the axon initial segment. Nat Neurosci 11:178-186. 
Larkum ME, Zhu JJ, Sakmann B (1999) A new cellular mechanism for coupling inputs arriving at different cortical layers. Nature 398:338-341.

Larkum ME, Zhu JJ, Sakmann B (2001) Dendritic mechanisms underlying the coupling of the dendritic with the axonal action potential initiation zone of adult rat layer 5 pyramidal neurons. J Physiol 533:447-466.

Latham A, Paul DH (1970) Climbing iibre responses of cerebellar Purkinje cells. J Physiol 207:56P-57P.

Llano I, Marty A, Armstrong CM, Konnerth A (1991) Synaptic- and agonist-induced excitatory currents of Purkinje cells in rat cerebellar slices. J Physiol 434:183-213.

Llinas R, Nicholson C (1971) Electrophysiological properties of dendrites and somata in alligator Purkinje cells. J Neurophysiol 34:532-551.

Llinás R, Sugimori M (1980a) Electrophysiological properties of in vitro Purkinje cell somata in mammalian cerebellar slices. J Physiol 305:171-195.

Llinás R, Sugimori M (1980b) Electrophysiological properties of in vitro Purkinje cell dendrites in mammalian cerebellar slices. J Physiol 305:197-213.

Llinás R, Nicholson C, Freeman JA, Hillman DE (1968) Dendritic spikes and their inhibition in alligator Purkinje cells. Science 160:1132-1135.

Magee JC, Carruth M (1999) Dendritic voltage-gated ion channels regulate the action potential firing mode of hippocampal CA1 pyramidal neurons. J Neurophysiol 82:1895-1901.

Mainen ZF, Sejnowski TJ (1996) Influence of dendritic structure on firing pattern in model neocortical neurons. Nature 382:363-366.

Mainen ZF, Joerges J, Huguenard JR, Sejnowski TJ (1995) A model of spike initiation in neocortical pyramidal neurons. Neuron 15:1427-1439.

Martina M, Yao GL, Bean BP (2003) Properties and functional role of voltage-dependent potassium channels in dendrites of rat cerebellar Purkinje neurons. J Neurosci 23:5698-5707.

Martinez FE, Crill WE, Kennedy TT (1971) Electrogenesis of cerebellar Purkinje cell responses in cats. J Neurophysiol 34:348-356.

McKay BE, Turner RW (2004) Kv3 K+ channels enable burst output in rat cerebellar Purkinje cells. Eur J Neurosci 20:729-739.

McKay BE, Molineux ML, Mehaffey WH, Turner RW (2005) Kv1 K+ channels control Purkinje cell output to facilitate postsynaptic rebound discharge in deep cerebellar neurons. J Neurosci 25:1481-1492.

McKay BE, Engbers JD, Mehaffey WH, Gordon GR, Molineux ML, Bains JS, Turner RW (2007) Climbing fiber discharge regulates cerebellar functions by controlling the intrinsic characteristics of Purkinje cell output. J Neurophysiol 97:2590-2604.

Miyakawa H, Lev-Ram V, Lasser-Ross N, Ross WN (1992) Calcium transients evoked by climbing fiber and parallel fiber synaptic inputs in guinea pig cerebellar Purkinje neurons. J Neurophysiol 68:1178-1189.

Monsivais P, Clark BA, Roth A, Häusser M (2005) Determinants of action potential propagation in cerebellar Purkinje cell axons. J Neurosci 25:464-472.

Nelson AB, Krispel CM, Sekirnjak C, du Lac S (2003) Long-lasting increases in intrinsic excitability triggered by inhibition. Neuron 40:609-620.

Palay SL, Chan-Palay V (1974) Cerebellar cortex. New York: Springer.

Palmer LM, Stuart GJ (2006) Site of action potential initiation in layer 5 pyramidal neurons. J Neurosci 26:1854-1863.

Perkel DJ, Hestrin S, Sah P, Nicoll RA (1990) Excitatory synaptic currents in Purkinje cells. Proc Biol Sci 241:116-121.

Pinsky PF, Rinzel J (1994) Intrinsic and network rhythmogenesis in a reduced Traub model for CA3 neurons. J Comput Neurosci 1:39-60.

Pugh JR, Raman IM (2006) Potentiation of mossy fiber EPSCs in the cerebellar nuclei by NMDA receptor activation followed by postinhibitory rebound current. Neuron 51:113-123.

Raman IM, Bean BP (1999) Ionic currents underlying spontaneous action potentials in isolated cerebellar Purkinje neurons. J Neurosci 19:1663-1674.

Rancz EA, Häusser M (2006) Dendritic calcium spikes are tunable triggers of cannabinoid release and short-term synaptic plasticity in cerebellar Purkinje neurons. J Neurosci 26:5428-5437.

Robinson HP, Kawai N (1993) Injection of digitally synthesized synaptic conductance transients to measure the integrative properties of neurons. J Neurosci Methods 49:157-165.

Ross WN, Werman R (1987) Mapping calcium transients in the dendrites of Purkinje cells from the guinea-pig cerebellum in vitro. J Physiol 389:319-336.

Sato Y, Miura A, Fushiki H, Kawasaki T (1992) Short-term modulation of cerebellar Purkinje cell activity after spontaneous climbing fiber input. J Neurophysiol 68:2051-2062.

Schiller J, Schiller Y, Stuart G, Sakmann B (1997) Calcium action potentials restricted to distal apical dendrites of rat neocortical pyramidal neurons. J Physiol 505:605-616.

Schmolesky MT, Weber JT, De Zeeuw CI, Hansel C (2002) The making of a complex spike: ionic composition and plasticity. Ann N Y Acad Sci 978:359-390.

Servais L, Bearzatto B, Schwaller B, Dumont M, De Saedeleer C, Dan B, Barski JJ, Schiffmann SN, Cheron G (2005) Mono- and dual-frequency fast cerebellar oscillation in mice lacking parvalbumin and/or calbindin D-28k. Eur J Neurosci 22:861-870.

Sharp AA, O’Neil MB, Abbott LF, Marder E (1993) Dynamic clamp: computer-generated conductances in real neurons. J Neurophysiol 69:992-995.

Silver RA, Momiyama A, Cull-Candy SG (1998) Locus of frequencydependent depression identified with multiple-probability fluctuation analysis at rat climbing fibre-Purkinje cell synapses. J Physiol 510:881-902.

Steuber V, Mittmann W, Hoebeek FE, Silver RA, De Zeeuw CI, Häusser M, De Schutter E (2007) Cerebellar LTD and pattern recognition by Purkinje cells. Neuron 54:121-136.

Stuart G, Häusser M (1994) Initiation and spread of sodium action potentials in cerebellar Purkinje cells. Neuron 13:703-712.

Stuart G, Schiller J, Sakmann B (1997) Action potential initiation and propagation in rat neocortical pyramidal neurons. J Physiol 505:617-632.

Swensen AM, Bean BP (2003) Ionic mechanisms of burst firing in dissociated Purkinje neurons. J Neurosci 23:9650-9663.

Swensen AM, Bean BP (2005) Robustness of burst firing in dissociated Purkinje neurons with acute or long-term reductions in sodium conductance. J Neurosci 25:3509-3520.

Turner RW, Lemon N, Doiron B, Rashid AJ, Morales E, Longtin A, Maler L, Dunn RJ (2002) Oscillatory burst discharge generated through conditional backpropagation of dendritic spikes. J Physiol Paris 96:517-530.

Vetter P, Roth A, Häusser M (2001) Propagation of action potentials in dendrites depends on dendritic morphology. J Neurophysiol 85:926-937.

Wadiche JI, Jahr CE (2001) Multivesicular release at climbing fiberPurkinje cell synapses. Neuron 32:301-313.

Welsh JP, Llinás R (1997) Some organizing principles for the control of movement based on olivocerebellar physiology. Prog Brain Res 114:449-461.

Williams SR (2004) Spatial compartmentalization and functional impact of conductance in pyramidal neurons. Nat Neurosci 7:961-967.

Williams SR, Stuart GJ (1999) Mechanisms and consequences of action potential burst firing in rat neocortical pyramidal neurons. J Physiol 521:467-482.

Williams SR, Stuart GJ (2002) Dependence of EPSP efficacy on synapse location in neocortical pyramidal neurons. Science 295:1907-1910.

Zagha E, Lang EJ, Rudy B (2008) Kv3.3 channels at the Purkinje cell soma are necessary for generation of the classical complex spike waveform. J Neurosci 28:1291-1300.

Zhu JJ (2000) Maturation of layer 5 neocortical pyramidal neurons: amplifying salient layer 1 and layer 4 inputs by $\mathrm{Ca}^{2+}$ action potentials in adult rat tuft dendrites. J Physiol 526:571-587. 